\title{
Waste Plastic-Modified Bitumen: Rheological Study
}

\author{
Mahmoud Abdel-Goad \\ Department of Petroleum and Chemical Engineering, College of Engineering, Sultan Qaboos University, Al-khod, P.O. Box. 33, \\ P.C. 123, Muscat, Sultanate of Oman
}

Received 6 October 2007; accepted 29 June 2008

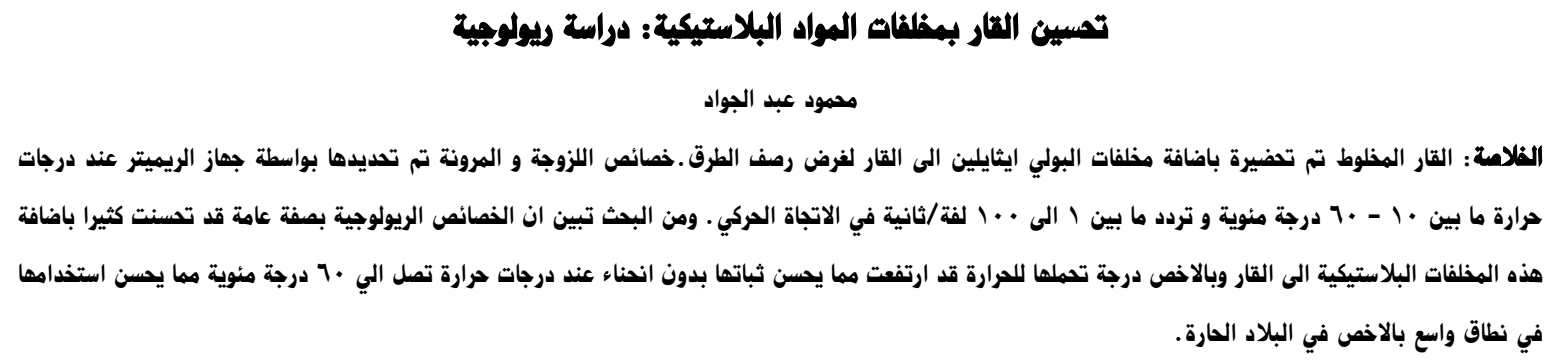

المثرهات المثتاهية: قار ، مخلفات بلاستيكية،ريولوجي ،جهد الاسترخاء، اللزوجة.

\begin{abstract}
Bitumen blends were prepared for road applications by the introduction of $9 \%$ of waste Polyethylene by weight (9 wt\%). The relaxation stress, relaxation and retardation spectrum and viscosity of bitumen blends were studied at different temperatures and compared to those of the original pure bitumen. These properties were tested using an ARESRheometer (Rheometric Scientific, Co.) equipment. The measurements were performed in the dynamic mode, plate-plate geometry of $8 \mathrm{~mm}$ diameter over the temperature range from -10 to $60^{\circ} \mathrm{C}$ and angular frequency $(\omega)$ varied from $10^{-1}$ to $10^{2} \mathrm{radian} / \mathrm{s}$. The relaxation stress and viscosity were modified by the addition of waste PE. The results also indicate that the incorporation of the waste PE enhances stability of the bitumen blends.
\end{abstract}

Keywords: Bitumen, Waste plastics, Relaxation stress, Relaxation spectrum, Viscosity

\section{Introduction}

Bitumen, which remains after vacuum distillation of crude oil, is a complex mixture of organic and inorganic compounds. The physical, mechanical, and rheological behavior of bitumen in road and building construction is governed by its chemical composition. For this reason, considerable effort goes toward widening the knowledge of this composition and relating it to performance (Anhorn and Badakhshan, 1994; Yui, 1997; Bonemazzi and Giavarini, 1999; Garcia-Perez, et al. 2001; Zhao, et al. 2001; Michaelian, et al. 2001; El Akrami, et al. 1999; Parker and McFarlane, 2000). The chemical composition of bitumen is very complex, although its components can be broadly categorized as maltenes and asphaltenes (Raki, et al. 2000; Yarranton, et al. 2000; Oh and Deo, 2002; Zhao, et al. 2001; Proctor, et al. 2001; Japanwala, et al. 2002). Asphaltenes are defined as the black-coloured fraction of bitumen that is insoluble in $n$-heptane. Maltenes, composed of saturated compounds, aromatic compounds and resins are soluble in n-heptane. The ratio of asphaltenes to the other constituents, and the maltenic

Corresponding author’s e-mail: mahmoud@squ.edu.om fraction composition have a significant effect on the viscoelastic properties of bitumens, and hence on their performance as road paving binders (Garcia-Morales, et al. 2004).

The high temperature sensitivity of bitumen makes it difficult to optimize both high- and low-temperature properties. The binders are too brittle at low temperatures and lack cohesion at high temperatures. The temperature sensitivity of straight-run bitumens can be reduced by adding polymer Herrington, et al. 1999).

The polymer addition allows an increase in the resistance of the binder to permanent deformation at high temperature. Besides, the fracture properties including critical stress intensity factor $\left(K_{1 C}\right)$ at low temperature of polymer modified bitumen were shown to be higher than those of the bitumen base (Champion-Lapalu, et al. 2002). Therefore, polymer-bitumen blends find considerable interest from different authors (Fawcett and Lor, 1992; Fawcett and McNally, 2000; Lu, 2000; Airey, 2003).

The application of polymeric materials in agriculture and horticulture has increased considerably in recent years, not only as replacement for traditional materials but also as a mean of effecting improvement. Thus, the application of plastics has led to a significant improvement in 
technological processes in the growing and storing of agricultural crops. As a result, a large amount of waste plastic films, containing LDPE, EVA and a minor proportion of stabilizers, are generated every year all over the world (Garcia-Morales, 2004). Therefore, the possibility of disposing of troublesome waste plastics within road bitumens provides an environmental and economical solution.

The rheological characterization of the bituminous materials is important to better understand its microstructure. Therefore, the rheological study has a considerable interest by different authors (Mehrotra, 1991; Eastick and Mehrotra, 1990, Airey, 2003; Mastrofini and Scarsella, 2001; Perez-Lepe and Martinez-Boza, 2003). It is well established that the linear behavior of bitumens is described by the general linear visco-elastic model. The rheological analysis is a sensitive and versatile thermal analysis technique, which measures the modulus (stiffness) and damping properties (energy dissipation) of materials as the material are deformed under periodic stress (Seha, et al. 1999).

Since the modulus of bitumen can vary by 3 to 4 orders in magnitude over the in-service temperature range, it was the objective of this work to modify the bitumen at inservice temperatures in hot countries by adding waste PE. Modified bitumen and neat bitumen will be characterized rheologically.

\section{Experimental Work}

\subsection{Materials and Preparation}

Bitumen blends were prepared by adding waste plastics to commercial bitumen (60/70). The waste PE bags were sorted from the garbage and shredded into coarse particles. The waste PE bags and the bitumen were weighed and heated individually in an oven until melting. Waste PE in molten state was poured into the molten bitumen, mechanically stirred to give a homogenous sample and then stored at $25^{\circ} \mathrm{C}$. The bitumen blends and the original neat bitumen samples were compression-molded at $70^{\circ} \mathrm{C}$ and 5 bars for 1 hour and shaped for the rheology measurements in a disc form with $8 \mathrm{~mm}$ diameter and 1 mm thickness.

\subsection{Measurements Procedure}

The rheological characterization was studied for neat bitumen and bitumen blends by using dynamic an ARESRheometer (Rheometric scientific) equipment in plateplate geometry of $25 \mathrm{~mm}$ diameter. The sample to be measured was placed on the lower plate and the upper plate was lowered until just contact the sample. The measurements were performed in the temperature range from 10 to $60^{\circ} \mathrm{C}$ and at an angular frequency $(\omega)$ in the range $10^{2}$ to $10^{-1}$ radian/s in the dynamic mode and the strain amplitude was kept at $1 \%$ in the linear viscoelastic regime. Six points per decade in frequency were obtained. The actual gap size is recorded electronically and allows absolute moduli to be determined.

\section{Results and Discussions}

The master curve is obtained by shifting the measured data at different temperatures ( $T$ ) into a single curve at a reference temperature $T_{0}$ as shown in Fig. 1. By using the time-temperature superposition principle which is described by Williams, Landel and Ferry (Ferry, 1980) as,

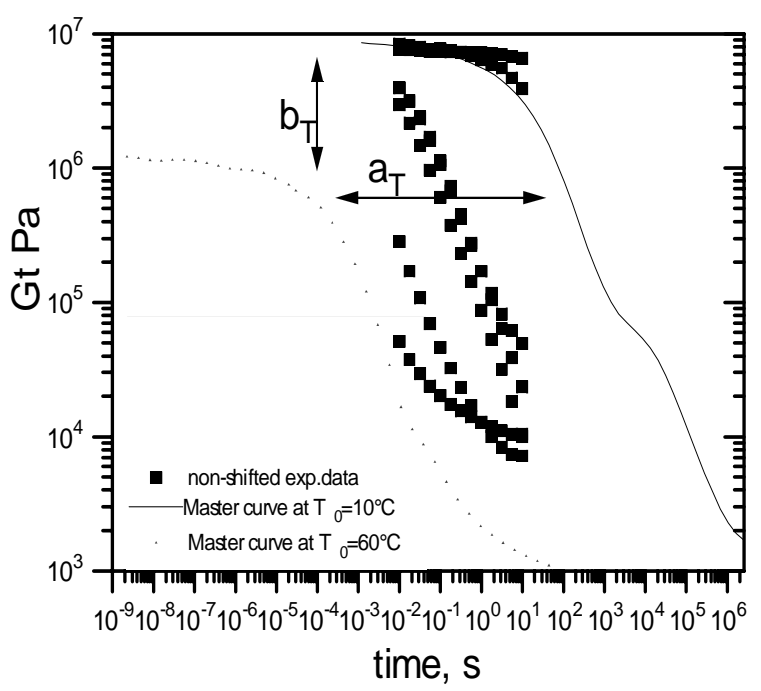

Figure 1. Non shifted experiments data of $G(t)$ at different temperatures are shifted into master curves at $T_{0}=25^{\circ} \mathrm{C}$ by using $a_{T}$ and $b_{T}$

$\log a_{T}=-C_{1}\left(T-T_{0}\right) /\left(C_{2}+\left(T-T_{0}\right)\right)$

Where $a_{T}$ is the horizontal shift factor, $T_{0}$ is a reference temperature, $T$ is measured temperature and constants $C_{1}$ and $C_{2}$ are material specific. $C_{1}$ and $C_{2}$ are roughly determined as listed in Table 1. $a_{T}$ of bitumen blends is plotted as a function of temperature in Fig. 2. In this Figure $a_{T}$ decreases with the increase in the temperature up to $25^{\circ} \mathrm{C}$ $\left(a_{T} \sim T^{-0.14}\right)$ then becomes nearly independent on the temperatures. The shift factor $\left(a_{T}\right)$ shifts the data obtained at different temperatures in the horizontal direction. In the vertical direction the experimental data are shifted by $b_{T}$ $\left(b_{T}=\rho^{T} / \rho_{0} T_{0}\right.$ [30] ), where $\rho$ is the material density. The effect of the temperature on $b_{T}$ is shown in Fig. 3 for bitumen blends. The vertical shift $\left(b_{T}\right)$ is nearly constant at low temperatures but after $25^{\circ} \mathrm{C}$ it falls rapidly ( $b^{T} \sim$ $T^{-0.17}$ ) with the increase of the temperature as shown in Fig. 3.

Table 1. Material constants

\begin{tabular}{lrr}
\multicolumn{1}{c}{ Material } & $\mathbf{C}_{1}$ & $\mathbf{C}_{2}$ \\
Bitumen & 24.9 & 196 \\
Bitumen with 9\%PE & 1.8 & 30
\end{tabular}




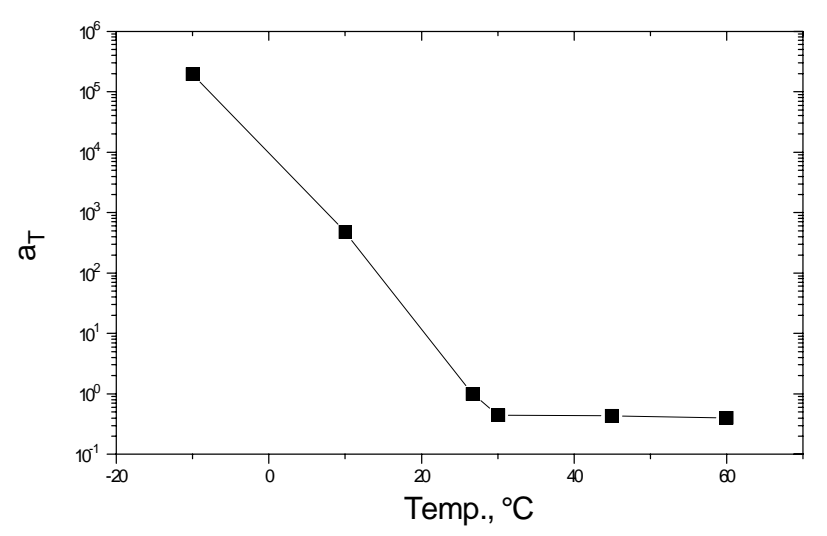

Figure 2. $\mathrm{a}_{\mathrm{T}}$ of bitumen/PE blend as a $\mathrm{f}$ unction of temperature at $\mathrm{T}_{0}=25^{\circ} \mathrm{C}$

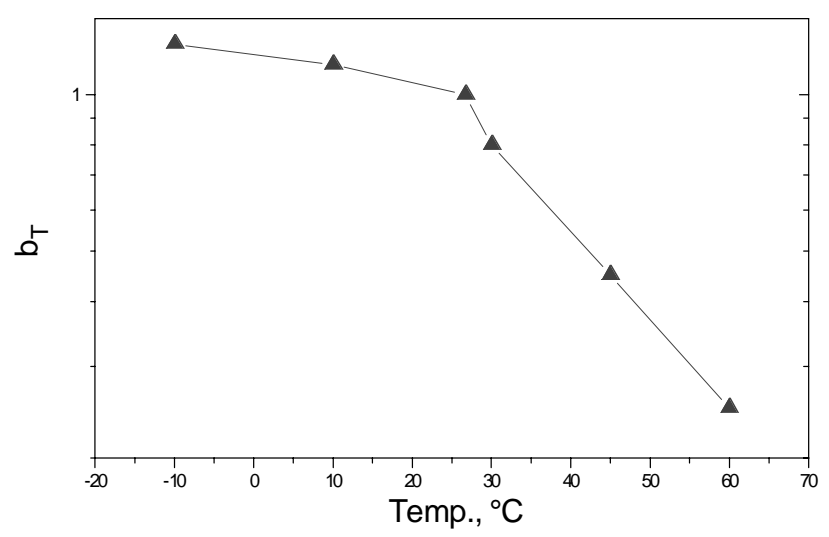

Figure 3. $\mathbf{b}_{\mathrm{T}}$ of bitumen/PE blend as a function of temperature at $\mathrm{T}_{0}=25^{\circ} \mathrm{C}$

The shear relaxation stresses $G(t)$ is plotted against time with logarithmic scales at $T_{0}=10,25$ and $60^{\circ} \mathrm{C}$ in Figs. 4-5 for neat bitumen and bitumen/PE blend. $G(t)$ is the relaxation stress at constant deformation. At long times of each $\mathrm{T}_{0}$, the master curve of each $G(t)$ shows flow regime which is related to the complete relaxation of the macromolecules and released from the restrictions of the entanglements. The time taken in the relaxation processes is called the longest relaxation time. In this regime, the viscous component is higher than the elastic component because of the release of the entanglements which are the responsible for the elasticity. Therefore, $G(t)$ decreases sharply and falls by many order of magnitude in this regime as shown in Fig. 4 and 5. At intermediate time of each master curve is located the rubbery zone that is the signature of the elasticity. As a result, $G(t)$ is independent on the time in this regime since the loss in the energy in every cycle of the deformation is minimum.

At short times the third regime of the viscoelastic behaviour is found only in the case of pure bitumen which is called dynamic glass transition because of the possibility to measure the neat bitumen samples at very low temperatures $\left(-10^{\circ} \mathrm{C}\right)$. The master curves at reference temperature $\left(10^{\circ} \mathrm{C}\right)$ are shifted toward the long time, those at $25^{\circ} \mathrm{C}$ appear to be in the intermediate and the master curves at reference temperatures $60^{\circ} \mathrm{C}$ are shifted toward the short time as shown in Fig. 4. This is because the time of relaxation of the entanglement chains is inversely proportional to temperature, since at low temperatures the chains take a long time in the relaxation processes, unlike at high temperatures. $G(t)$ modulus at $60^{\circ} \mathrm{C}$ is lower than at $25^{\circ} \mathrm{C}$ and $G(t)$ at $25^{\circ} \mathrm{C}$ is lower than at $10^{\circ} \mathrm{C}$ as seen in Figs. 4 and 5 .

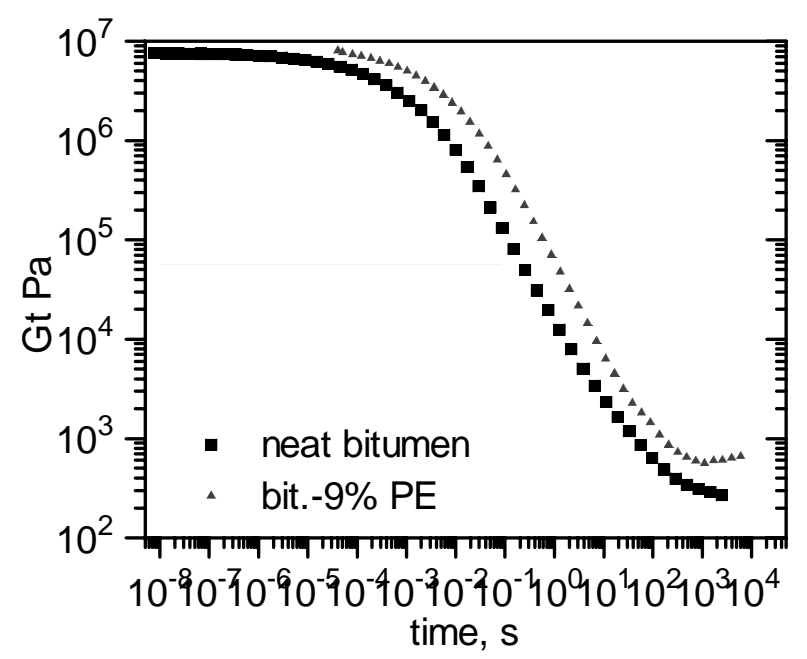

Figure 4. $G(t)$ of bitumen/PE and neat bitumen at $T_{0}=25^{\circ} \mathrm{C}$

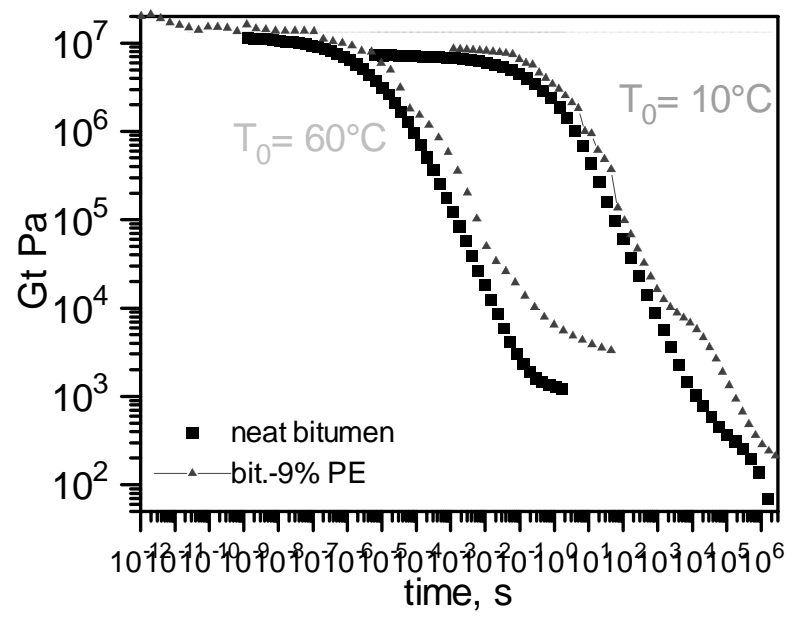

Figure 5. $G(t)$ of bitumen/PE and neat bitumen at $T_{0}=10$ and $60^{\circ} \mathrm{C}$

Figures 4 and 5 are evidence that the incorporation of the waste plastics into the bitumen increases the relaxation stress over all the temperatures and time ranges. This increase in $G(t)$ moduli is more noticeable at long times and high temperatures as shown in these Figures. Where the values of $G(t)$ modulus at 5 seconds and $10^{\circ} \mathrm{C}$ is 2 times higher than this of neat bitumen by the addition of 9\% PE as shown in Fig. 4. This factor reaches up to 7 at 50 seconds (the same temperature) as shown in Fig. 4. The ratio $G(t)_{b i t .-9 \% P E} / G(t)_{\text {bitumen }}$ at the end of flow regime in the cases of $T_{0}=10,25$ and $60^{\circ} \mathrm{C}$ are 3,6 and 10 . This means that the bitumen/PE blend is more stable than neat bitumen at high temperatures for long times. This is due to the formation of the bitumen-polymer network which 
increases the stiffness and strength of the bitumen blends. That is confirmed too in Figs. 6 and 7. In these Figures, the shear equilibrium creep $(\mathrm{Je}$ ) is logarithamically plotted versus time for bitumen and bitumen/PE blend. The addition of $\mathrm{PE}$ to bitumen enhances ( $\mathrm{Je}$ ) in particular at long times and the differences among ( $\mathrm{Je}$ ) values of bitumen/PE blend is more observable at long times due to the stability of the bitumen-PE network.

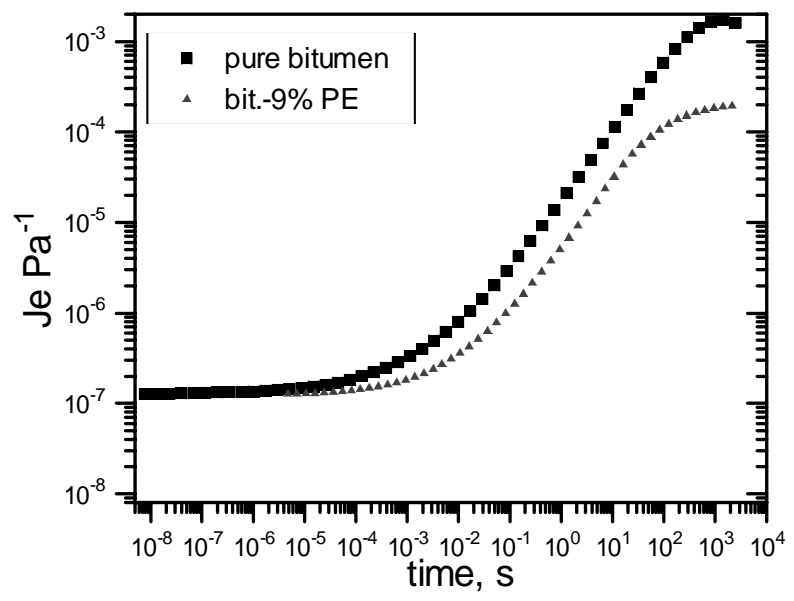

Figure 6. Je of bitumen/PE and neat bitumen at $T_{0}=25^{\circ} \mathrm{C}$

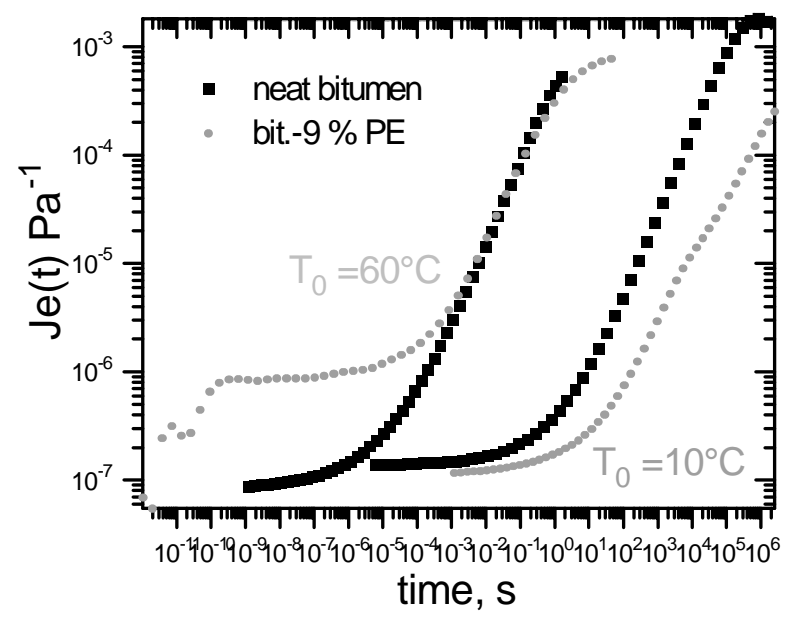

Figure 7. Je of bitumen/PE and neat bitumen at $T_{0}=10$ and $60^{\circ} \mathrm{C}$

The relaxation $(H(t))$ and retardation $(L(t))$ spectrum of neat bitumen and bitumen/PE blend are plotted as a function of time at $25^{\circ} \mathrm{C}$ in Figs. 8 and 9. $H(t)$ and $L(t)$ indicate the distribution of relaxation and retardation mechanisms, respectively in different regions of the time scale. They show a broad spectrum of relaxation and retardation times. A broad mechanical relaxation, observed at $25^{\circ} \mathrm{C}$, is associated with the collapse of a compact structure, constituted by asphaltene particles surrounded by solid resin. The addition of PE to bitumen modifies this relaxation.

The values of $H(t)$ increase by the addition of waste PE to bitumen, in particular, at long times as shown in Fig. 8. This is clear at 40 seconds where $H(t)$ of bitumen blend is higher than that of neat bitumen by a factor 2 with the addition of $9 \% \mathrm{PE}$ as shown in Fig. 8. This factor becomes 6 at 100 seconds as shown in Fig. 8. The same scenario is observed in $L(t)$ (Fig. 9) since at 40 Seconds the addition of $9 \% \mathrm{PE}$ to bitumen results in changing the values of $L(t)$ for neat bitumen from $5.0 \times 10^{-5}$ to $4.3 \times$ $10^{-1} \mathrm{~Pa}^{-1}$ as shown in Fig. 9. However, at 1000 seconds the values of $L(t)$ are $5.0 \times 10^{-3}$ and $5.7 \times 10^{-4} \mathrm{~Pa}^{-1}$ for pure bitumen and bitumen/9\%PE blend, respectively as shown in Fig. 9. This as explained earlier due to the increase in the stiffness and strength of the bitumen by the incorporation of the $\mathrm{PE}$.

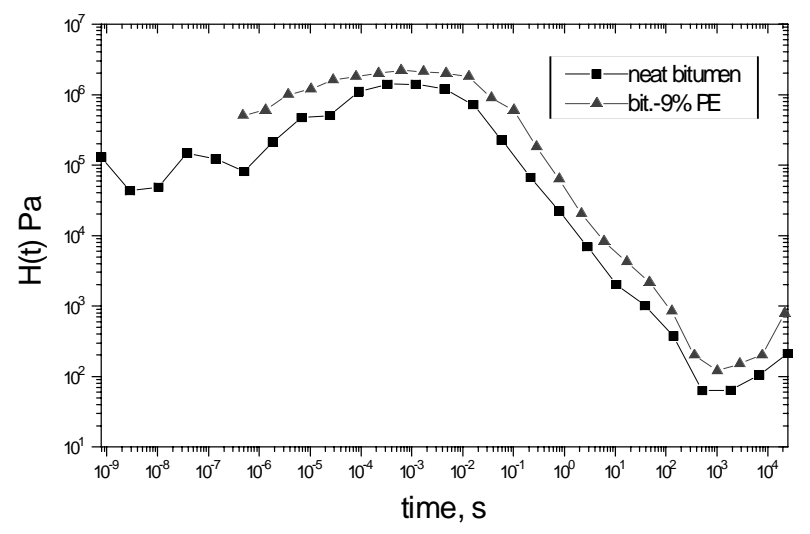

Figure 8. $\mathrm{H}(\mathrm{t})$ of bitumen/PE and neat bitumen at $T_{0}=25^{\circ} \mathrm{C}$

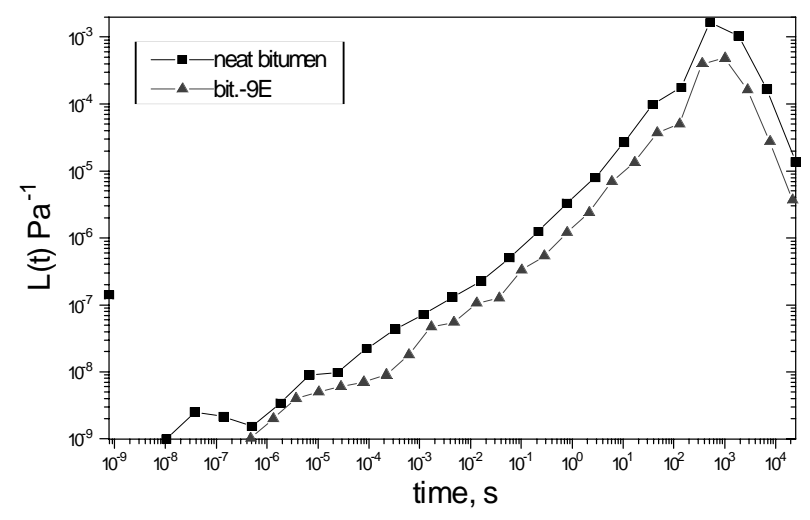

Figure 9. $\mathrm{L}(\mathrm{t})$ of bitumen/PE and neat bitumen at $\mathrm{T}_{0}=25^{\circ} \mathrm{C}$

The complex viscosity $\left(\eta^{*}\right)$ as a function of temperature for neat bitumen and bitumen blends at $\omega=0.1$ radian/s is plotted in Fig. 10. As shown in this figure, the incorporation of the waste PE into the bitumen increases the viscosity over all the temperatures range. This is because the viscosity of the bitumen matrix is higher than neat bitumen. The complex viscosity $\left(\eta^{*}\right)$ of the blends at high temperatures are higher than at low temperatures. As shown in Fig. 10 the values of $\eta^{*}$ at $15^{\circ} \mathrm{C}$ increase from $5.0 \times 10^{4}$ (neat bitumen) to $5.7 \times 10^{5} \mathrm{~Pa}$.s by the addition $9 \% \mathrm{PE}$, respectively but at $60^{\circ} \mathrm{C}$ the differences among the values of $\eta^{*}$ are high. These values are $2.7 x$ $10^{5}$ and $5.7 \times 10^{5}$ Pa.s for neat bitumen and bitumen/9\%PE blend, respectively as shown in Fig. 10. This difference is due to the change in bitumen compo- 
nents considerably at $\sim 40^{\circ} \mathrm{C}$, particularly the ratio of the asphaltenes to the maltenes (the main components of bitumen) which has a significant effect on the viscoelastic properties of bitumen.

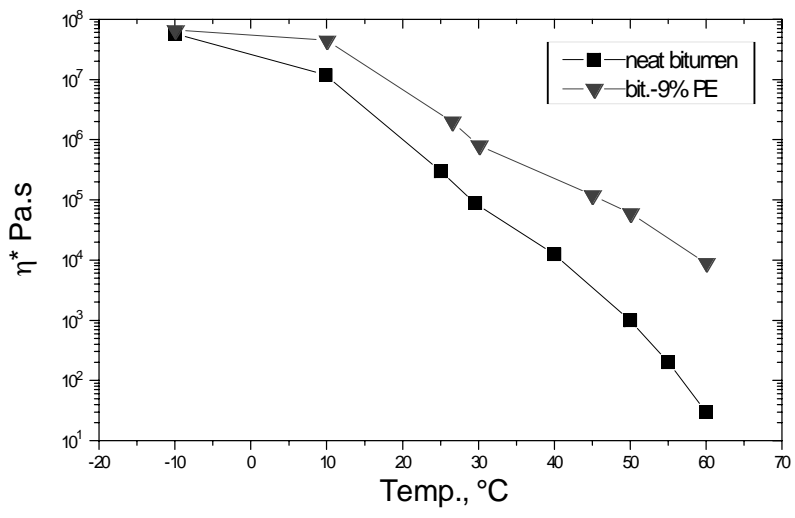

Figure 10. $\eta^{*}$ of bitumen/PE and neat bitumen as a function of temperature at $\omega=0.1 \mathrm{rad} / \mathrm{s}$

\section{Conclusions}

Bitumen blends were prepared as a road paving binders by the introduction of $9 \%$ waste PE in a molten state followed by mechanical mixing. The materials were rheologically characterized using an ARES- Rheometer (Rheometric Scientific, Co.) equipment. The measurements were performed in the dynamic mode, plate-plate geometry of $25 \mathrm{~mm}$ diameter over the temperature range from -10 to $60^{\circ} \mathrm{C}$ and angular frequency $(\omega)$ varied from $10^{2}$ to $10^{-1}$ radian/s.

The relaxation stress, relaxation and retardation spectrum and viscosity of bitumen blends were studied at different temperatures and compared to those of the original neat bitumen. The results showed that the relaxation stress and viscosity were developed by the incorporation of $9 \%$ of waste plastics into neat bitumen. The results also showed that the incorporation of the waste plastics enhances stability of the bitumen blends. An increase in these properties resulted from the incorporation of waste plastics into bitumen, this increase is significant particularly at high temperatures for a long time. As a consequence, the use of waste PE bags can be considered a suitable alternative from both environmental and economical points of view.

\section{Acknowledgments}

The financial support by the International Bureau in Germany, helpful discussions of Dr. W. Pyckhout and Dr. S. Khale at FZJ, Germany are greatly acknowledged.

\section{References}

Abdel-Goad, M., 2000, "PhD Thesis," Muenster University, Germany.
Airey, G.D., 2003, "Fuel," Vol. 82, pp. 1709-1719.

Airey, G.D., 2003, "Fuel," Vol. 82, pp. 1709-1719.

Anhorn J. L. and Badakhshan A., 1994, " Fuel," Vol. 73, pp. 1499-1503.

Bonemazzi F. and Giavarini C., 1999, "Journal of Petroleum Science and Engineering," Vol. 22, pp. 1724.

Champion-Lapalu, L., Wilson, A., Fuchs, G., Scramoncin, C., Martin, D., Planche, J.P., 2002, "Energy \& Fuels," pp. 143-147.

Eastick, R. R. and Mehrotra, A. K., 1990, "Fuel Processing Technology," Vol. 26, pp. 25-37.

El Akrami, H.A., Yardim, M.F., Ekinci, E., 1999, "Energy \& Fuels," Vol. 13, pp. 1030-1036.

Fawcett, A. H. and McNally, T., 2000, "Polymer," Vol. 41, pp. 5315-5326.

Fawcett, A.H. and Lor, S.K., 1992, "Polymer," Vol. 33, pp. 2003-2006.

Ferry, J.D., 1980 "Viscoelastic Properties of Polymers", 3rd ed. ( Wiley, New York).

García-Morales, M., Partal, P., Navarro, F. J., MartínezBoza, F., Gallegos, C., González, N., González, O. and Muñoz, M.E., 2004, "Fuel," Vol. 83, pp. 31-38.

García-Morales, M., Partal, P., Navarro, F.J., MartínezBoza, F., Gallegos, C., González, González, O., and Muñoz, M.E., 2004, "Fuel," Vol. 83, pp. 31-38.

Garcìa-Pèrez M., Chaala A., Yang J. and Roy C., 2001, "Fuel," Vol. 80, pp. 1245-1258.

Herrington, P.R., Wu, Y. and Forbes, M.C., 1999, "Fuel," Vol. 78, pp. 101-110.

Japanwala, S., Chung, K.H., Dettman, H.D., Gray, M.R., 2002, "Energy \& Fuels," Vol. 16, pp. 477- 484.

Lu, X. and Isacsson, U., 2000, "Polymer Testing," Vol. 20, pp. 77-86.

Mastrofini, D. and Scarsella, M., 2001, "Fuel," Vol. 42, p. 24.

Mehrotra, A. K., 1991, "Journal of Petroleum Science and Engineering," Vol. 5, pp. 261-272.

Michaelian K.H., Zhang S.L., Hall R.H. and Bulmer J.T., 2001, "Spectrochimica Acta Part A: Molecular and Biomolecular Spectroscopy," Vol. 57, pp. 73-81, 2001.

Oh, K., Deo, M.D., 2002, "Energy \& Fuels," Vol. 16, pp. 694-699.

Parker, R.J., McFarlane, R.A., 2000, "Energy \& Fuels," Vol. 14, pp. 11-13.

Pérez-Lepe, A., Martínez-Boza, F.J., Gallegos, C., González, O., Muñoz, M.E. and Santamaría, A., 2003, "Fuel," Vol. 82, pp. 1339-1348.

Proctor, L.M., Toy, E., Lapham, L., Cherrier, J., Chanton, J.P., 2001, "Environ. Sci. Technol," Vol. 35, pp. 14201424.

Raki, L., Masson, J.F., Collins, P., 2000, "Energy \& Fuels," Vol. 14, pp. 160-163.

Saha, A.K., Das, S., Bhatta, D. and Mitra, B.C., 1999, "J. of Applied Polymer Science," Vol. .71, pp. 15051513.

Yarranton, H.W., lboudwarej, H.A., Jakher, R., 2000, 
"Ind. Eng. Chem. Res," Vol. 39, pp. 2916-2924.

Yui S., 1997, "Fuel and Energy Abstracts," Vol. 38, pp. 78.

Zhao, L. S. Kotlyar, J. R. Woods, B. D. Sparks, K. Hardacre and K. H. Chung, 2001, "Fuel," Vol. 80, pp. 1155-1163.

Zhao, Y., Gray, M.R., Chung, K.H., 2001, "Energy \& Fuels," Vol. 15, pp. 751-755. 